Mollo, L. Emuze, F., and Smallwood, J. (2019). "Using Standardized Work to Prevent Construction Accidents." In: Proc. $27^{\text {th }}$ Annual Conference of the International. Group for Lean Construction (IGLC), Pasquire C. and Hamzeh F.R. (ed.), Dublin, Ireland, pp. 1059-1068. DOI: https://doi.org/10.24928/2019/0117. Available at: 〈www.iglc.net>.

\title{
USING STANDARDIZED WORK TO PREVENT CONSTRUCTION ACCIDENTS
}

\author{
Lesiba Mollo', Fidelis Emuze², and John Smallwood ${ }^{3}$
}

\begin{abstract}
The work done on construction sites is high risk, unsafe and could result in work-related accidents. The effect of accidents often impacts the social and economic integrity of the workers and their productivity negatively. The reported study in this paper investigated 'how standardized work prevents accidents on construction sites?' A single case research design was used to collect the primary data through semi-structured interviews and focus group interviews. The collected data were analyzed thematically. From the findings, it was discovered that improper working conditions related to scaffolds often causes accidents on construction sites. In effect, the use of standardized work would help to eradicate improper working conditions that lead to accidents because it helps project supervisors/engineers to avoid errors and omissions. For standardized work to be successful, the project supervisors should actively address the behavioral problems of the workers. Therefore, it is recommended that there is a need to conduct further research that would establish the strength of the standardized work in improving health, safety and well-being (HSW) of people in the construction.
\end{abstract}

\section{KEYWORDS}

Accidents, construction, health, safety and wellbeing, standardized work

\section{INTRODUCTION}

The construction industry is one of the most dangerous industries causing a high number of accidents worldwide (Andersen et al., 2018). Accidents in construction influences production output negatively. This is because construction work is laborintensive in nature and the workers are valued resources that makes significant contributions to the performance and quality of the projects (Ghodrati et al., 2018). The construction site is a workplace where most of the accidents experienced on sites are linked to the workers' decisions and actions (Durdyev et al., 2017).

However, the outcomes of the accident's causations in the workplace does not only affect the victims negatively but also the society, including the family, community,

1 Lecturer, Department of Built Environment, Central University of Technology, Free State, Private Bag X20539, Bloemfontein, 9301, South Africa, Tel: (051) 507 3523, Email: 1mollo@cut.ac.za.

2 Professor and Head, Department of Built Environment, Central University of Technology, Free State, Private Bag X20539, Bloemfontein, 9301, South Africa, Tel: (051) 507 3089, Email: femuze@cut.ac.za. ; Research Associate: Nelson Mandela University

3 Professor, Department of Construction Management, Nelson Mandela University, Po Box 77000, Port Elizabeth, 6031, South Africa, Tel: (041) 5042790 / 551. Email: John.Smallwood@ mandela.ac.za. 
organization and clients (Hallowell, 2010). According to González et al. (2016), the processes of investigating accidents reduce productivity because of stoppages or interruption of activities. Thus, accidents on construction sites reduce productivity, and increase project costs through medical care, delays, lost working days, and other penalties (Forteza et al., 2017).

Therefore, to solve these reported problems of accidents in the construction industry, standardized work is recommended by Micklewright (2010). The purpose of standardized work is to help organizations to improve quality and eliminate waste to achieve the continuous improvement that adds value to the clients (Saggin et al., 2017). Standardized work can be adopted to help construction managers to improve safety on construction sites (Fireman et al., 2018). Thus, the objective of this paper is to report on research that investigated 'how standardized work prevents accidents on construction sites?' According to Forbes and Ahmed (2011), the philosophy of standardized work is to help project supervisors to identify problems so that they can continue to improve the situations.

\section{STANDARDIZED WORK PRACTICE}

Standardized work is a philosophy in the Toyota Production System (TPS), which sets a baseline for 'Kaizen' known as 'continuous improvement' in the workplace (Fireman et al., 2018). Standardized work is described as a working procedure that helps to develop the best working methods and sequences for each trade of work and each worker to be tasked (Fin et al., 2017). During the implementation of standardized work, it is important for management or project supervisors to standardize or regulate the working procedures in order to stabilize the process before continuous improvement can be applied (Pereira et al., 2016). According to Gomez and Hamid (2018), continuous improvements is described as a process that helps organizations to achieve high performance by eliminating defects, reducing process and product waste, managing efficient production and thus improving productivity.

It is reported that the adoption of standardized work is to help managers to eliminate waste while exploiting performance in the workplace and the operation of each worker (Pereira et al., 2016). Therefore, it can be argued that standardized work is a suitable method to prevent construction accident. Also, in a lean practice accident is described as a type of waste (Aziz and Hafez, 2013). For instance, the impact of construction accidents usually causes lots of negative consequences relating to nonappearance of workers, delays, permanent disability of the victims, and cost of accident investigations (Shao et al., 2019). These highlighted factors by Shao et al., (2019) contribute to waste because they do not add value to the organizations.

Essentially, standardized work consists of three elements, namely; takt time, standard work sequence, and standard work in process (Micklewright, 2010). The description of these three elements of standardized work shows that:

- Takt time is defined as the rate or speed of time needed to produce items or units of a product in the workplace, and it is issued based on the ratio between time and production demand for the product (Fin et al., 2017). However, takt time is not 
measured or observed, but it is calculated based on the percentage of the available time by the output required (Pereira et al., 2016).

- Standard work sequence is defined as an adopted working procedure in which a set of items or units are produced in the safest manner using the best methods. However, the work sequence is different from the order of processes and product flow (Fireman et al., 2018).

- Standard work in process inventory is defined as a systematic model that provides the minimum measure of work needed to maintain the pace of production in a continuous flow, without idle times (Fireman et al., 2018).

The indicate that standardized work sets assist in achieving high levels of productivity, quality and safety in the workplace (Fin et al., 2017). Micklewright (2010: 202) quoted a statement by Henry Ford in 1988, that 'today's standardization is the necessary foundation on which tomorrows improvement will be based. If you think of standardization as the best you know today, but which is to be improved tomorrow, you get somewhere. But if you think of standards a confining, then progress stops.'

\section{RESEARCH METHODOLOGY}

As indicated in the previous sections, the reported study investigated 'how standardized work prevents accidents on construction sites?' To meet this objective, a construction site project in Bloemfontein, South Africa was selected. Thus, this study adopted a single case design (Yin, 2014), which helped the researcher to determine whether standardized work can be adapted to prevent accidents in the construction industry. The research design provided a platform to refocus future research investigation regarding how to improve the health, safety, and well-being (HSW) of people in construction using standardized work in the construction industry.

The primary data of this single case study were collected using semi-structured interviews and focus group interviews. To be precise, nine participants were interviewed for this case study (Table 1). These nine participants were selected purposeful as recommended by Miles et al. (2014). The reason to select the participants purposeful is that the researcher was seeking to collect the data from construction professions with lived experiences. The participants were working on the same construction project.

Thus, open-ended research questions were used as a guideline to help the researcher to collect the data using a face-to-face interview mode (Miles et al., 2014). There were two interview sessions, the first session was between the researcher and the project leaders, namely a construction manager, site engineer, safety manager, and foreman. The aim of this first interview session was to identify the causes of the accidents on construction sites. The second interview session was conducted through focus group and there were two focus groups. The first focus interview was between the researcher and the project leaders and the second focus group interview was between the researcher and the artisans. The aim of the second interview sessions was to determine how standardized work can be adapted to prevent accidents on construction sites.

The use of focus group helped the researcher to understand the reported problems and to provide solutions, as it gathered different opinions from the construction professions as 
suggested by Krueger and Casey (2015). During the focus group interviews, each participant was encouraged to share their perception and point of view without interference. The collected data were analyzed thematically as demonstrated by Miles et al., (2014). The interviews were held at the site office and the duration of each interview was between 30 - 60 minutes. The research data were collected between September and November 2018.

Table 1: Research sample

\begin{tabular}{|c|c|c|c|}
\hline \multicolumn{2}{|c|}{ Participants } & \multirow{2}{*}{$\begin{array}{c}\text { Number } \\
1\end{array}$} & \multirow[t]{2}{*}{ Percentage } \\
\hline \multirow{5}{*}{ Project leaders } & Construction manager & & \\
\hline & Site engineer & 1 & \multirow{4}{*}{$56 \%$} \\
\hline & Safety manager & 1 & \\
\hline & Senior foreman & 1 & \\
\hline & Junior foreman & 1 & \\
\hline \multirow[t]{2}{*}{ Artisans } & Bricklayers & 3 & \\
\hline & Plaster & 1 & $44 \%$ \\
\hline \multicolumn{2}{|c|}{ Total participants } & 9 & $100 \%$ \\
\hline
\end{tabular}

\section{RESULTS AND DISCUSSION}

The subsequent sessions present and discuss the research findings. The first session investigates the first research questions ' what contribute to accidents on construction sites?' and the second asks 'how standardized work could prevent accidents?. However, during the first interview sessions, the background of the study was introduced to the interviewees, particularly on standardized work in the construction industry.

\section{WHAT CONTRIBUTE TO ACCIDENTS ON CONSTRUCTION SITES?}

Most of the interviewees reported that the working conditions and working on scaffolds are the contributing factors of accidents on construction sites. The term working conditions refer to the working environment and all the present conditions influencing the workers in the workplace, such as working hours, physical aspects, legal rights and responsibility organizational culture workload and training (Ali et al., 2013). From the findings, it is discovered that working conditions are often enthused by the desire of the workers to reach a high level of productivity. For instance, a safety manager is quoted as follows: 
'There are reported cases about our workers complaining that often their supervisors prioritize productivity over their safety. For instance, often they are given instruction to deliver tasks in an unreasonable period and they are restricted from diverting one of their colleagues to clean and pack the working space they are working in. They argue that their supervisors would tell them that their priorities are to deliver their task as quickly as possible.'

A construction manager had a similar response to a site engineer. They argued that the employees of their subcontractors are responsible for creating a poor working environment. In their opinions, the employees of subcontractors create non-value adding activities, which result in poor housekeeping. For instance, the results of poor housekeeping are observed as the unpacked broken bricks laying all over the site, tools and equipment that are not stored properly, personal items that are not stored and machines that are not packed correctly. Therefore, poor housekeeping might cause errors and violations which might result in unintended injuries or accidents in the workplace. However, a safety manager disputed the statement of the construction manager and the site engineer, blaming poor housekeeping on the subcontractors' employees. In his arguments, he mentioned that the construction managers and supervisors are to be blamed for poor housekeeping because they ignore the factors causing poor housekeeping while focusing on a high level of productivity from their team members.

A senior foreman stated that the results of poor working conditions are influenced by numerous factors such as limited working space on the sites. The impact of little spaces on sites forces construction managers to design a complex site layout, especially for projects in the urban areas. Also, the weather conditions are another factor contributing to poor working conditions, especially during the summer periods. This is because, during the summer periods, it rains in South Africa and the wet surface influences the working environment. The perception reinforced the report by Winge et al. (2019) that the working condition is influenced by numerous factors which include wet conditions, thermal stresses, light, noise and other physical and climate factors causing hazards and risks in the workplace.

In terms of working on scaffolds. From the findings, it was discovered that there are various risks and hazards which are experienced by the workers while working on scaffolds. For instance, a construction manager is quoted as follows:

'It is important for management to calculate the impact which might result from the accidents should a scaffold collapse or an employee fall off while working on a scaffold. It is critical that management must be able to understand how they are going to deal with such situations because one can never be able to predict the effect of human failure in the industries.'

Furthermore, a site engineer explained that scaffold erectors must always check and test the resilience of scaffold equipment upon erecting the scaffolds. This is important because a scaffold could only support a limited amount of weight, which includes materials and the workers. According to a junior foreman, failure to control the working conditions of the workers at height, especially those who are working on a scaffold is hazardous to the workers at the lower levels. He is quoted as follows: 
'I once witnessed an incident whereby a worker was hit by a piece of brick, which was falling from the fourth floor, approximately 4 meters above ground level. Luckily, the brick only hit a worker on his right shoulder and the impact of the incident was not severe. After the incident, the worker was rushed to a hospital for medical examination and it was confirmed by a doctor that the worker is not seriously hurt and was put on special leave for a month to recover from home.'

Furthermore, it was also reported that it is important for construction organizations to have the medical screening of the workers before the start of the project. A safety manager explained that the results of the worker's medical fitness help them to know the health status of individuals and those who will be able to work at height. He further explained that working on a scaffold is a high risk and there are other external factors which increase risks, such as the hot temperature during the summer period (the sun temperature increases close to 38 Degrees Celsius in summer). Therefore, the challenges which individuals are working at on the scaffold and the issues of fatigue is better imagined than witnessed. The conditions, in turn, occurs due to high productivity demand by the supervisors. In addition, a senior foreman stated that the actions and behaviors of the workers are a contributing factor to risks created when working on scaffolds. He further explained that often the workers working at height on scaffolds tend to become tired and try to take shortcuts, which results with accidents. For instance, a senior foreman says, 'it is known that when you're working on scaffolds you are not supposed to throw your tools or equipment or waste materials to the ground, but you find workers who are still throwing their equipment to the ground especially when knocking off.'

\section{HOW STANDARDIZED WORK COULD PREVENT ACCIDENTS?}

In the previous section, the researcher identified causal factors causing construction accidents. A major identified accident factor to be solved include working on scaffolds. To solve the problem, standardized work is adopted as recommended by Micklewright (2010).

To solve the problem of working conditions, a researcher asked the interviewees to distinguish the causes of working conditions. From the previous section, it was discovered that poor housekeeping is a major factor causing poor working conditions on construction sites. It was discovered that poor housekeeping is a waste that creates non-value adding activity and hazards that might cause errors and violations on the sites. For instance, it was reasoned by one the artisan from the $2^{\text {nd }}$ focus group interviews that their supervisors do not allocate period or time for housekeeping activities on sites such as cleaning the site and storing the used equipment and tools.

In addition, it is reported by some member of the project leaders from the $1^{\text {st }}$ focus group interviews, that 'Takt Time (which is an element of standardized work)' can be related to a critical path method. Takt time relates to a critical path method because it determines the time needed by the workers or management to complete a task. Failure by management or the workers to keep up with the time programmed to complete a task often lead to failure which might cause defects or accidents on sites. From the $1^{\text {st }}$ focus group interviews, a construction manager is quoted as follows:

'By studying the definition of 'Takt Time' I can now conclude that it is like the critical path method because 'Takt Time' is the rate at which a person needs to complete a product 
in order to meet the client's needs, and while the critical path helps to identify the activities that must be completed on time in order to deliver the entire projects to the client's needs.'

It is reported by a safety manager from the $1^{\text {st }}$ focus group interviews that the construction manager must start to include the housekeeping as part of the task or activity plans, and the workers who will be responsible for housekeeping sequence must perform the work within the designed period of the designed task.

In terms of working on scaffolds, it was discovered that there are several risks from hazards that are experienced by the workers when working on scaffolds. For instance, a safety manager stated the actions and decisions of the workers often results with errors and violations, and there are natural events such as rain and hot weather contributing to errors and violations. The interviewees from $2^{\text {nd }}$ focus group interviews said that they would recommend that their supervisors would stop giving the bricklayer working on scaffolds the same deadline to complete their task with those working on the ground floor or working on a concrete slab. This is because workers who are working on scaffolds are exposed to more risks than those who are working on the ground floor. It is further reported by a site engineer from the $2^{\text {nd }}$ focus group interviews that it is critical that the managers must include the safety measure and risk control of working on scaffolds when planning and measuring the time to complete tasks which require the use of the scaffold. This is because workers who are working at a height above 2 meters are required to wear a safety harness. The use of safety harness restricts the movement of the workers and the working space on scaffolds restrict their speed of construction. Thus, it is reported that working on scaffolds reduces the speed of the workers and this influences productivity negatively.

The application of standardized work is presented in Table 2. Hence Table 2 indicates the three important steps which must be followed in the process of adopting standardized work to prevent accidents on construction sites. The use of standardized work is responsible to help site management to reduce accident by firstly identifying the root causes of accident on a project site, as indicated in Table 2, Step 1. The identification of the causes of accident would help site management to be able to prepare the appropriate safety training that would focus on helping the workers to drive down the causes of the accident, which is indicated in Step 2. In Step 3, the knowledge transfer or safety training prepared for the workers in Step 2 would help the workers to have the skills to continue with their tasks and improve productivity on a site project. The application of standardized work is developed based on the analysis of the standardized work literature and the findings presented in this reported research study.

Table 2: The application of standardized work

\begin{tabular}{ccc}
\hline Important steps & Key points & Reasons \\
\hline $\begin{array}{c}\text { Step 1: Identify the causes of } \\
\text { the problems. }\end{array}$ & $\begin{array}{c}\text { You must breakdown the } \\
\text { construction activities or task } \\
\text { and identify hazards which }\end{array}$ & $\begin{array}{c}\text { This will help in the discovery } \\
\text { of the root causes of the } \\
\text { reported problems } \\
\text { (construction accidents). }\end{array}$ \\
\hline
\end{tabular}



(For instance, poor working
conditions )
Step 2: Prepare the workers to solve the problems

(For instance, the workers must be taught about the safety regulations and how to identify hazards and risks when working on sites)

Step 3: Improve the operations

(For instance, allow housekeeping to form part of the job task) might cause injury or accidents in the workplace.

(For instance, it is reported that poor housekeeping, limited working spaces and extreme weather conditions might cause errors and violations on site)

It is important to improve the skills and knowledge of the workers through training.
This will prepare the workers to have the skills and knowledge of the work.
The workers must be given the jobs task and be corrected if an error is experienced.

Introduce continuous improvement for the job task.

\section{CONCLUDING REMARKS}

The reported research assessed how standardized work could prevent accidents on construction sites. The process of adopting standardized work to reduce accidents in the construction industry is highlighted in Table 2, through the three important steps. From the literature and findings, it can be concluded that indeed construction accidents are a major concern in the construction industry. It is reported by the interviewees that working on scaffolds is a major concern. Poor housekeeping is identified as a contributing factor to poor working conditions. Thus, it is recommended that a construction manager must start to include housekeeping practice as part of the action plan when designing the critical path methods. This will help the workers to promote housekeeping practice while delivering the planned task without interfering with productivity. This would also help the construction team to continue to improve the working conditions without causing any construction accidents. Hence it is highlighted in Table 2 that the adaptions of standardized work to solve the reported construction accidents should follow the three important steps.

The use of standardized work could also help construction managers to set as a baseline to promote safety by eliminating errors and violations which might be produced when working on scaffolds. It is critical for management to fully understand the risks and hazards when working on scaffolds. This will help management to improve the working conditions of the workers working on scaffolds. Therefore, it is important for management to identify 
the causes of the problems when adopting standardized work. This will help management to set a standardization which would provide the baseline to improve the reported problem on the construction site. There is a need to conduct further research that would establish the strength of the standardized work in improving health, safety and well-being (HSW) of people in the construction.

\section{REFERENCES}

Andersen, L.P., Nordam, L., Joensson, T., Kines, P., and Nielsen, K.J. (2018). Social identity, safety climate and self-reported accidents among construction workers. Construction Management and Economics, 36(1), 22-31.

Ali, A. A. (2013). Working Conditions and Employees' Productivity in Manufacturing Companies in Sub-Saharan African Context: Case of Somalia. Educational Research International, 2(2), 67-78.

Aziz, R.F., and Hafez, S.M. (2013). Applying lean thinking in construction and performance improvement. Alexandria Engineering Journal, 52, 679-695.

Durdyev, S., Mohamed, S., Lay, L.M., and Ismail, S. (2017). Key Factors Affecting Construction Safety Performance in Developing Countries: Evidence from Cambodia. Construction Economics and Management, 17(4), 48-50.

Fin, J. V. (2017). Improvement based on standardized work: an implementation case study. Brazilian Journal of Operations \& Production Management, 14(3), 388395.

Fireman, M. S. (2018). The role of Slack in Standardized Work in construction: An Exploratory Study. In: Proc. 26th Annual Conference of the International. Group for Lean Construction (IGLC) (pp. 1313-1322). Chennai, India: IGLC.

Forbes, L.H., and Ahmed, S.M. (2011). Modern Construction Lean Project Delivery and Integrated Practices. New York: CRC Press.

Forteza, F. C.-G. (2017). Occupational risks, accidents on sites and economic performance of construction firms. Safety Science, 94, 61-76.

García de Soto, B. A.-J. (2018). Productivity of digital fabrication in construction: Cost and time analysis of a robotically built wall. Automation in Construction, 92, 297311.

Ghodrati, N. Y. (2018). Unintended consequences of management strategies for improving labor productivity in construction industry. Journal of Safety Research, 67, 107-116.

Golizadeh, H. H. (2018). Digital engineering potential in addressing causes of construction accidents. Automation in Construction, 95, 284-295.

Gomez, C.P., and Hamid, H. (2018). ISO and lean can contribute to a culture of continuous improvement. In V. González (Ed.), In: Proc. 26thAnnual Conference of the International. Group for Lean Construction (IGLC) (pp. 305-315). Chennai, India: IGLC.

González, V. B. (2016). Analysis of the causes and consequences of accidents. Revista Ingeniería de Construcción, 31(1), 5-16. 
Hallowel, M. (2010). Cost effectiveness of construction safety programme elements. Construction Management and Economic, 28(1), 25-34.

Krueger, R.A., and Casey, M.A. (2015). Focus Groups: A practical Guide for Applied Research (5 ed.). Los Angeles: SAGE Publications.

Micklewright, M. (2010). Lean ISO 9001: Adding Spark to Your ISO 9001 QMS and Sustainability to Your Lean Efforts. Milwaukee, USA: ASQ Quality Press.

Miles, M. H. (2014). Qualitative Data Analysis: A Methods Sourcebook (3 ed.). Los Angeles: SAGE Publications.

Pereira, A. A. (2016). Reconfigurable Stanardized Work in a Lean Company - a case study. Changeable, Angile, Reconfigurable \& Virtual Production, 52, 239-244.

Saggin, A. B. (2017). Standardized Work: Practical Examples in a Brazilian Construction Company. In K. S. Walsh (Ed.), In: LC3 2017 Volume II - Proceedings of the 25th Annual Conference of the International Group for Lean Construction (IGLC) (pp. 713-720). Heraklion, Greece: IGLC.

Shao, B. H. (2019). Fatal accident patterns of building construction activities in China. Safety Science, 111, 253-263.

Winge, S. A. (2019). Causal factors and connections in construction accidents. Safety Science, 141, 130-141.

Yin, R. (2014). Case Study Research: Design and Methods. Los Angeles: Sage Publications. 